Саратовский государственный медиицнский университет им. В.И. Разумовского

\title{
Оптимизация тактики
} обследования и лечения женщин репродуктивного возраста с патологией шейки матки при хронических цервицитах и вагинитах

\author{
У.В. Столярова, к.м.н., И.Е. Рогожина, д.м.н., проф., И.Н. Скупова, \\ М.В. Кузнецова, Н.С. Кузнецов, А.С. Асыркин
}

Адрес для переписки: Ульяна Владимировна Столярова, stolyarova.ulyana@yandex.ru.ru

Для цитирования: Столярова У.В., Рогожина И.Е., Скупова И.Н. и др. Оптимизация тактики обследования и лечения женщин репродуктивного возраста с патологией шейки матки при хронических цервицитах и вагинитах // Эффективная фармакотерапия. 2021. T. 17. № 19. C. $8-14$.

DOI 10.33978/2307-3586-2021-17-19-8-14

Проанализирована эффективность лечения пациенток репродуктивного возраста с хроническими неспецифическими экзо- и эндоцервицитами и вагинитами при наличии доброкачественных и предраковых заболеваний шейки матки легкой степени. Представлена сравнительная характеристика комбинированного препарата для интравагинального применения Эльжина и интравагинального метронидазола с пероральным флуконазолом. Показаны преимущества препарата Эльжина в плане предоперационной подготовки перед применением радиоволновых эксиизионных и хирургических методов. Проведена оценка эфбективности, переносимости и безопасности двух указанных видов терапии. Отмечается, что препарат, содержащий орнидазол 500 мг, преднизолон 3 мг, эконазол 150 мг и неомицин 65000 МЕ, уменьшает выраженность воспалительных процессов, что благоприятно влияет на результаты радиоволновых и хирургических методов лечения доброкачественньх и предраковых заболеваний шейки матки на фоне хронических, длительно существующих неспецифических экзо- и эндоцервицитов и вагинитов.

Ключевье слова: патология шейки матки, иервицит, вагинит, репродуктивный возраст, Эльжина

A ктуальность проблемы лечения доброкачественных и предраковых заболеваний (CIN, SIL) шейки матки определяется их широким распространением, недостаточной эффективностью существующих методов лечения, вероятностью прогрессирования интраэпителиальных неоплазий до плоскоклеточных и железистых карцином, что представляет собой единый патологический процесс, формирующийся на фоне первоначально доброкачественных, неопухолевых нарушений многослойного плоского и цилиндрического эпителия [1-5]. Предраковые заболевания (CIN, SIL) шейки матки, несмотря на визуальную локализацию поражения и доступность диагностики, продолжа- 
ют занимать одно из ведущих мест в структуре гинекологической патологии. Частота их выявления достигает 10-20\% среди всех заболеваний влагалищной части шейки матки. Распространенность предраковых поражений шейки матки в популяции различна: для LSIL (CIN l) - 1,5-7,7\%, для HSIL (CIN II, CIN III) - 0,4-1,5\%.

Особую значимость проблема приобретает у женщин репродуктивного возраста с доброкачественными и предраковыми (CIN, SIL) заболеваниями шейки матки на фоне хронических, длительно существующих неспецифических экзо- и эндоцервицитов и вагинитов.

При сочетании доброкачественных заболеваний шейки матки с нарушением ее архитектоники вследствие деформации из-за старых разрывов или гипертрофии, а также при обнаружении предраковых (CIN, SIL) заболеваний шейки матки возникает необходимость в применении хирургических методов лечения $[3,4,6]$. С этой целью обычно используют радиоволновые петлевые и конусовидные эксцизии, а также ножевую ампутацию шейки матки и реконструктивно-пластические операции с восстановлением нормальной анатомии цервикального канала.

В структуре воспалительных заболеваний женской половой сферы патологические изменения влагалища и шейки матки, связанные с условно-патогенной флорой, имеют первостепенное значение [1, 3-12]. Аэробные или неспецифические вагиниты и экзои эндоцервициты, при которых анаэробные лактобациллы, превалирующие в норме, заменяют аэробные бактерии Aerobic vaginitis, главным образом Streptococcus spp., Staphylococcus spp., бактерии семейства Enterobacteriaceae (Escherichia coli, Klebsiella spp., Citrobacter spp., Enterobacter spp., Serratia spp., Proteus mirabilis, Morganella morganii), - самый распространенный вариант патологического процесса $[1,4,5,7,8]$. Обусловленный выработкой ферментов бактериальными агентами, он совместно с тканевыми протеазами и протеазами аккумулированных лейкоцитов вызывает значительную деструкцию тканей. Основной спектр возбудителей аэробных вагинитов представлен на рис. 1.

При неспецифических экзо- и эндоцервицитах и вагинитах наблюдается выраженная воспалительная реакция слизистой оболочки $[1,7,10]$. Репарация происходит посредством секреции провоспалительных цитокинов (интерлейкинов $1,2,6,8,12$, фактора некроза опухоли альфа, интерферона гамма, гранулоцитарно-макрофагального колониестимулирующего фактора), активации фагоцитов и усиления их эффекторного потенциала (фагоцитоза, продукции активных форм кислорода), функций Т-киллеров. При хронических заболеваниях женских половых органов, особенно при урогенитальных нарушениях, выявляются признаки выраженного нарушения репарации $[4,5,10,11]$. Процесс восстановления целостности ткани после уничтожения патогенного фактора в результате регенерации лабильных клеток слизистой оболочки, сохранивших способность

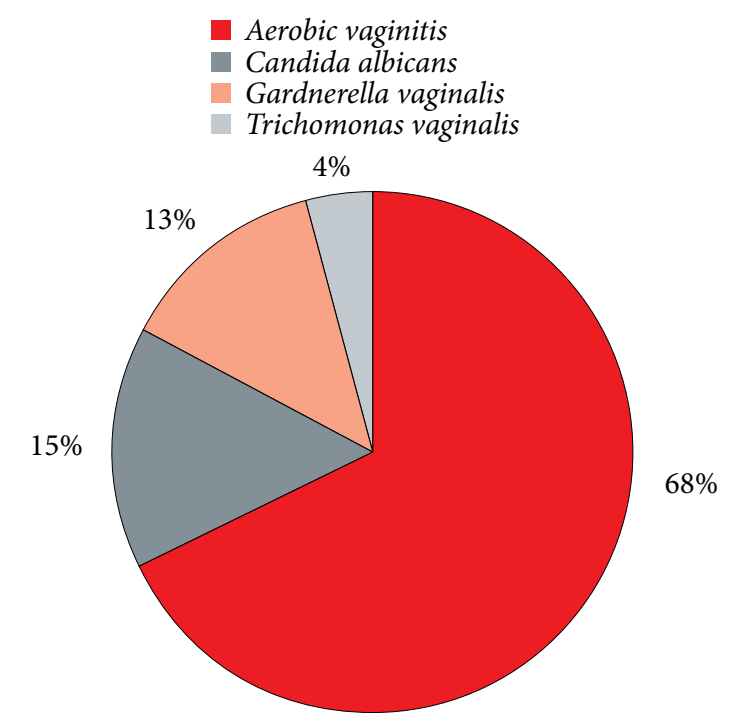

Рис. 1. Основной спектр возбудителей аэробных вагинитов

к пролиферации и соответственно поддержанию тканевого гомеостаза, претерпевает значительные изменения.

За счет анатомических и физиологических особенностей строения (узкий цервикальный канал, наличие в нем слизистой пробки, содержащей секреторный иммуноглобулин А, лизоцим и другие вещества, обладающие бактерицидными свойствами) шейка матки служит биологическим барьером. Ее защитные механизмы нарушаются при травмах после родов, абортов, инвазивных диагностических процедур, когда инфекция свободно проникает в половые пути и воспалительный процесс возникает прежде всего в экзо- и эндоцервиксе $[4-6,8,9]$. В результате нарушается кровоснабжение урогенитального тракта, снижается коллагенообразование. Таким образом, процесс репарации после инвазивных процедур имеет затяжное течение и сопровождается рядом осложнений. Они обычно возникают на фоне хронических вялотекущих экзо- и эндоцервицитов и вагинитов, характеризующихся неярко выраженной клинической картиной, затрудняющей постановку диагноза указанных заболеваний.

У пациенток с экзо- и эндоцервицитами и вагинитами при осмотре отмечаются болезненность, отечность, гиперемия, петехиальные высыпания, поверхностные эрозии слизистой оболочки шейки матки, стенок и преддверия влагалища, что наиболее выражено при длительно рецидивирующем хроническом воспалении.

Комплекс лабораторных исследований для диагностики неспецифических экзо- и эндоцервицитов и вагинитов включает:

- рН-метрию и аминотест с 10\%-ным раствором гидроокиси калия. В случае воспалительного процесса, обусловленного аэробной флорой, $\mathrm{pH}$ влагалищного содержимого превышает 5,0, а аминотест отрицательный $[8,11]$; 
- микроскопическое исследование мазка из цервикального канала и отделяемого из влагалища - позволяет оценить степень воспалительного процесса (лейкоцитарную реакцию), состояние микрофлоры, а также выявить специфические воспалительные процессы, обусловленные трихомонадами, внутриклеточными диплококками, грибами рода Candida. Кроме того, определяются число лактобацилл и характер коккобациллярной микрофлоры;

- культуральный метод - практически всегда основан на получении и изучении чистой культуры микроорганизмов, что полностью исключает возможность получения представления о микробиоте как о системе. Традиционные микробиологические методы не только не способны предоставить полную качественную и количественную характеристику микробиоценоза влагалища, но и не позволяют проанализировать особенности популяционных взаимодействий микроорганизмов $[1-3,8]$;

- полимеразную цепную реакцию (ПЦР) - определение видового состава микрофлоры влагалища. Помогает выявить наличие и количество патогенной и условно-патогенной микрофлоры и возбудителей инфекций, передаваемых половым путем.

Современная концепция терапевтического подхода при подготовке пациенток к эксцизионным радиоволновым и хирургическим методам лечения при доброкачественных и предраковых заболеваниях (CIN, SIL) шейки матки должна заключаться как в устранении факторов, провоцирующих воспаление, так и в активации репаративных процессов. Это позволяет сократить продолжительность периода заживления тканей, снизить вероятность осложнений и рецидивов заболеваний. Исходя из этого актуально применение антибактериальных препаратов с учетом результатов бактериологического исследования и лекарственных средств с комбинированным противовоспалительным, репаративным и регенерирующим эффектами $[4-6,8,9,11,12]$. Несомненно, при назначении терапии женщинам с эндоцервицитами и вагинитами необходимо принимать во внимание характер патологического процесса, сопутствующую патологию, гормональный фон, виды предшествующей терапии и результаты комплексного обследования.

С учетом полинаправленности лечения и необходимости воздействия на различные звенья патологического процесса интерес представляет комбинированный препарат для интравагинального применения, содержащий орнидазол 500 мг, преднизолон 3 мг, эконазол 150 мг и неомицин $65000 \mathrm{ME}$.

Орнидазол - противопротозойный и противомикробный препарат, производное 5-нитроимидазола. Механизм действия заключается в биохимическом восстановлении 5-нитрогруппы орнидазола внутриклеточными транспортными протеинами анаэробных микроорганизмов и простейших. Восстановленная 5-нитрогруппа орнидазола взаимодействует с ДНК клеток микроорганизмов, ингибируя синтез их нуклеиновых кислот, что приводит к гибели бактерий.

Активен в отношении Trichomonas vaginalis, Gardnerella vaginalis, Giardia intestinalis, Entamoeba histolytica, Lamblia spp., а также облигатных анаэробов Bacteroides spp. (в том числе B. fragilis, B. distasonis, B. ovatus, B. thetaiotaomicron, B. vulgatus), Fusobacterium spp., Veillonella spp., Prevotella (P. bivia, P. buccae, $P$. disiens) и некоторых грамположительных микроорганизмов (Eubacterium spp., Clostridium). К орнидазолу нечувствительны аэробные микроорганизмы. Эконазол оказывает местное противогрибковое (фунгицидное или фунгистатическое в зависимости от концентрации) и антибактериальное (бактерицидное) действие. Тормозит биосинтез эргостерола и других стеролов, регулирующих проницаемость клеточной стенки грибов. Ингибирует биосинтез триглицеридов и фосфолипидов грибов. Кроме того, нарушает окислительную и перекисную активность ферментов, что приводит к созданию токсических внутриклеточных концентраций перекиси водорода (может вызвать повреждение субклеточных органелл) и клеточному некрозу. Обладает широким спектром действия. Эконазола нитрат активен (как in vitro, так и по результатам клинических исследований при лечении ряда инфекций) в отношении большинства штаммов микроорганизмов: Trichophyton rubrum, T. mentagrophytes, T. tonsurans, Microsporum canis, M. audouinii, M. gypseum, Epidermophyton floccosum, а также Candida albicans, Malassezia furfur (Pityrosporum orbiculare) и Corynebacterium minutissimum. По данным исследований in vitro, эконазола нитрат активен в отношении штаммов микроорганизмов (клиническая значимость этих данных не определена), таких как дерматофиты (Trichophyton verrucosum), дрожжеподобные грибы (C. guilliermondii, C. parapsilosis, C. tropicalis). Активен также в отношении некоторых плесневых грибов (Aspergillus, Cladosporium, Scopulariopsis brevicaulis) и грамположительных бактерий (Streptococcus spp., Staphylococcus spp.).

Неомицин - бактерицидное, антибактериальное средство широкого спектра действия. Проникает через клеточную мембрану бактерий, связывается со специфическими белками-рецепторами на 30S-субъединице рибосом. Нарушает образование комплекса транспортной и матричной РНК и останавливает синтез белков (бактериостатический эффект). При более высоких концентрациях повреждает цитоплазматические мембраны микробной клетки с быстрой последующей гибелью (бактерицидный эффект). Активен в отношении ряда грамположительных и грамотрицательных микроорганизмов, в том числе Staphylococcus spp., Str. pneumoniae, E. coli, Salmonella spp., Shigella spp., C. diphtheriae, Bacillus anthracis, Proteus spp. Устойчивость микроорганизмов к неомицину развивается медленно. Не влияет на анаэробную микрофлору, патогенные грибы, вирусы. 
Преднизолон - универсальный мембранопротектор, эффективен в борьбе с воспалительными процессами. Как антиаллергенное и иммуносупрессивное средство часто используется в различных лекарственных формах. Способствует быстрому клиническому улучшению - снижает зуд, жжение, диспареунию.

Как показали результаты исследований, терапия комбинированными местными препаратами с противомикробным, противопротозойным, противогрибковым и противовоспалительным действием эффективна в восстановлении вагинального микробиома $[1,2,4,5,7,8,12]$. По данным различных авторов, эффективность такого лечения достигает 90-95\%. К настоящему моменту оптимальная схема терапии бактериальных вагинальных нарушений при предраковых заболеваниях шейки матки легкой степени (LSIL) четко не определена.

Вопрос оценки эффективности, переносимости и безопасности препарата для интравагинального применения, содержащего орнидазол 500 мг, преднизолон 3 мг, эконазол 150 мг, неомицин $65000 \mathrm{ME}$ и назначаемого женщинам репродуктивного возраста, остается актуальным.

Препарат уменьшает выраженность воспалительных процессов, что благоприятно отражается на результатах проведенных радиоволновых и хирургических методов лечения доброкачественных и предраковых (CIN, SIL) заболеваний шейки матки на фоне хронических, длительно существующих неспецифических экзо- и эндоцервицитов и вагинитов.

Целями проведенного исследования стали:

- оптимизация предоперационной подготовки перед эксцизионными радиоволновыми и хирургическими методами лечения и повышение эффективности лечения хронических рецидивирующих неспецифических экзо- и эндоцервицитов и вагинитов у женщин репродуктивного возраста;

- оценка эффективности местного применения противомикробного, противогрибкового, противопротозойного, противовоспалительного препарата Эльжина при хронических рецидивирующих неспецифических экзо- и эндоцервицитах и вагинитах у женщин репродуктивного возраста.

\section{Материал и методы}

В исследовании приняли участие 60 женщин, которым, по данным клинико-лабораторных методов исследования, был поставлен диагноз рецидивирующего неспецифического экзо- и эндоцервицита или вагинита на фоне доброкачественных или предраковых заболеваний шейки матки легкой степени (LSIL). Пациентки были разделены на две группы. Основную составили 30 женщин, которые в качестве предоперационной подготовки перед радиоволновыми или хирургическими методами лечения шейки матки получали местную терапию комбинированным препаратом для интравагинального применения (орнидазол 500 мг, преднизолон 3 мг, эконазол 150 мг, неомицин 65000 ME) в виде вагинальных таблеток по одной таблетке вечером (перед сном) на протяжении девяти дней. 30 пациенток группы сравнения получали метронидазол интравагинально по 250 мг два раза в сутки в течение десяти дней и флуконазол внутрь однократно (150 мг). После предоперационной подготовки проводилось радиоволновое или хирургическое лечение шейки матки в различных объемах.

Критериями отбора пациенток в исследование служили:

$\checkmark$ наличие фоновых или предраковых заболеваний шейки матки легкой степени (LSIL);

$\checkmark$ подтвержденный диагноз рецидивирующего неспецифического экзо- и эндоцервицита или вагинита;

$\checkmark$ возраст от 16 до 45 лет;

$\checkmark$ клиническая симптоматика вагинита или цервицита: выделения из влагалища, дискомфорт в области промежности, вагинальный зуд, жжение, иногда дизурические явления;

$\checkmark$ изменения в мазках, окрашенных по Граму: повышение содержания лейкоцитов, отсутствие специфических микробных агентов;

$\checkmark$ изменение рН влагалища $>4,5$;

$\checkmark$ аномальная кольпоскопическая картина 1-й степени на фоне хронического воспаления в зоне трансформации 1-го или 2-го типов;

$\checkmark$ согласно данным цитологического исследования мазков с экто- и эндоцервикса и зоны их стыка (при предраковых заболеваниях шейки матки легкой степени (LSIL)), изменения только в клетках базального и парабазального слоев. Слоистость эпителильного пласта многослойного плоского эпителия не нарушена;

$\checkmark$ наличие условно-патогенной микрофлоры влагалища (при ПЦР-исследовании) - одного или нескольких видов: бактерии семейства Enterobacteriaceae (E. coli, Klebsiella spp., Citrobacter spp., Enterobacter spp., Serratia spp., P. mirabilis, M. morganii), Streptococcus spp., Staphylococcus spp. и проч.

Кольпоскопическое исследование (расширенная кольпоскопия с применением эпителиальных тестов с 3\%-ной уксусной кислотой и 2\%-ным раствором Люголя, а также зеленых фильтров с целью детализации характера васкуляризации) проводилось на цифровом видеокольпоскопе Sensitec SLC-200. Всем пациенткам выполнялось цитологическое исследование мазков с экзо- и эндоцервикса и зоны их стыка с трактовкой результатов по Папаниколау (РАР-тест) и терминологической системе Бетесда (Terminology Bethesda System, TBS). Bce пациентки дали согласие на участие в исследовании. Критерии исключения из исследования:

$\checkmark$ инфекции, передаваемые половым путем;

$\checkmark$ инфекции вирусной этиологии (вирус простого герпеса, вирус папилломы человека, цитомегаловирус);

$\checkmark$ тяжелая экстрагенитальная патология;

$\checkmark$ предраковые заболевания шейки матки умеренной и тяжелой степени (HSIL, CIN II-III); 
$\checkmark$ индивидуальная непереносимость компонентов препарата Эльжина;

$\checkmark$ отказ от сотрудничества с исследователями и визитов в клинику в назначенные дни.

Для статистической обработки данных использовали парный t-критерий Стьюдента для зависимых совокупностей. Данный метод применяется в исследованиях со сравнением данных до и после. Различия считались достоверными при $\mathrm{p}<0,005$.

\section{Результаты}

Анамнестические данные продемонстрировали, что у всех пациенток имели место частые рецидивы неспецифических цервицитов и вагинитов, при лечении которых ранее применялись препараты антимикробного действия, антисептики.

Комплексное микробиологическое исследование базировалось на культуральной диагностике и микроскопии мазков, окрашенных по Граму, а также дополнительных тестах (рН-метрия, аминный тест), ПЦР - комплексном исследовании мазка из урогенитального тракта на наличие наиболее распространенных инфекций, передаваемых половым путем (Neisseria gonorrhoeae, Chlamydia trachomatis, Mycoplasma genitalium, T. vaginalis).

Культуральное исследование с использованием сред Эндо, селективных угольных питательных сред, питательных сред для бактероидов, жидких и твердых сред Сабуро проводилось для определения видового и количественного состава отделяемого из влагалища и цервикального канала.

Основным клиническим симптомом были выделения из влагалища с неприятным запахом (100\% слу-

Лейкоцитоз
Кокки
Отсутствие лактобацилл
Аэробная флора
рН > 4,5
Условно-патогенная флора

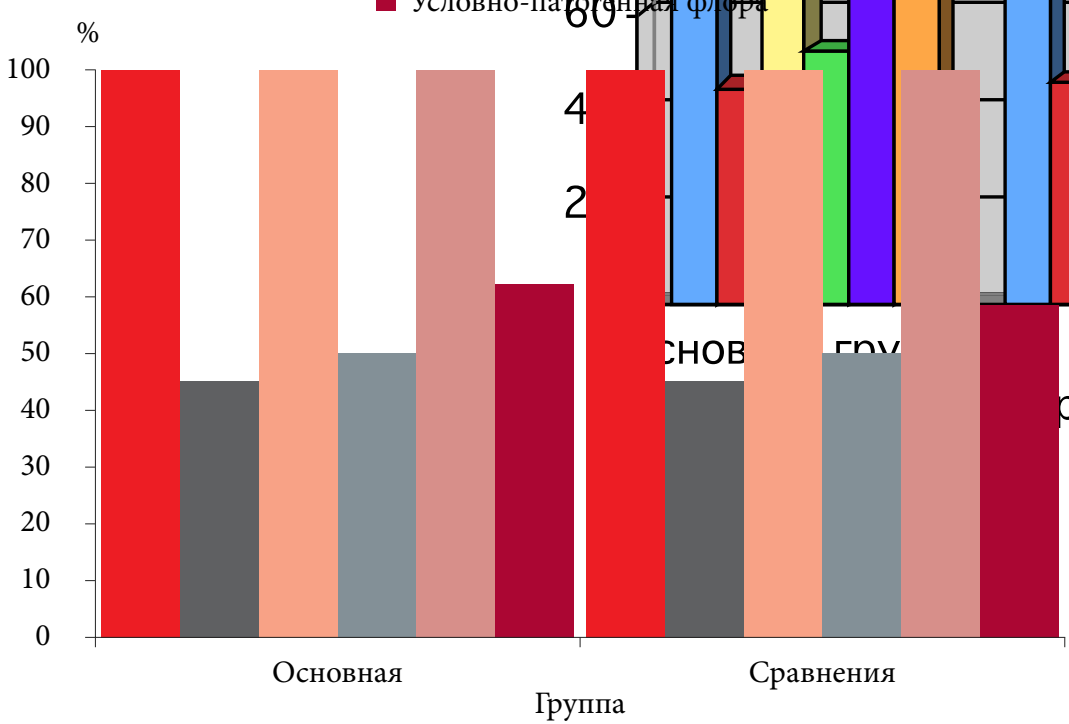

Рис. 2. Лабораторнье показатели отделяемого из влагалища у пациенток до течения чаев). При микроскопии выделений влагалища и цервикального канала обнаружены лейкоцитоз $(100 \%)$, мелкие коккобактерии и кокки (45 и 46\% соответственно). Отмечалось отсутствие лактобацилл (100\%), аэробной флоры (52,5 и 54\% соответственно). Значение $\mathrm{pH}$ влагалищных выделений превысило 4,5 (100\%). Частота идентификации условно-патогенной флоры значимо не различалась между группами $(64,5 \%$ - в основной и $56,0 \%$ - в группе сравнения) (рис. 2).

Осуществлялся забор материала с эктоэндоцервикса и зоны стыка для онкоцитологического исследования. Необходимо отметить, что при цитологическом исследовании мазки класса I по классификации Папаниколау (нормальная цитологическая картина) были зафиксированы у 5,2\% обследованных. Чаще (92,8\% случаев) определялись мазки класса II по Папаниколау (с изменением морфологии клеточных элементов, обусловленным воспалительным процессом во влагалище и на шейке матки), что по TBS (1991) соответствовало доброкачественным изменениям клеток из-за воспаления, а также ASCUS (атипическим плоскоэпителиальным клеткам неопределенного значения). Мазки класса III по Папаниколау (с единичными клетками с аномалиями цитоплазмы и ядер), по TBS-LSIL, выявлены у 2\% пациенток. Цитологические заключения, соответствующие мазкам классов IV и V по TBS-HSIL, служили критерием исключения больных из исследования.

При кольпоскопическом исследовании аномальная картина 1-й степени на фоне хронического воспаления (плоский ацетобелый эпителий с неровными, нечеткими краями, тонкие мозаика и пунктация в зонах трансформации 1-го и 2-го типов) обнаружены у 95,6\% женщин основной группы и 89,6\% группы сравнения. Данные процессы обусловлены как реактивными воспалительными изменениями плоского эпителия, так и его атипией, характерной для предраковых состояний многослойного плоского эпителия легкой степени (LSIL).

Анализ динамики клинических симптомов показал, что такие проявления, как диспареуния, зуд, жжение, патологические выделения из половых путей, в основной группе прекращались уже через два-три дня от начала лечения. В то же время в группе сравнения клиническое улучшение наблюдалось в более поздние сроки - через 6-8 дней. На десятый день выделения прекратились у 94,2\% пациенток основной группы и 52,4\% группы сравнения. Неприятный запах выделений из влагалища к десятому дню лечения не беспокоил 92 и 45\% женщин основной группы и группы сравнения соответственно. Динамика исчезновения объективных проявлений воспалительной реакции со стороны слизистых оболочек при визуальном и кольпоскопическом контроле на фоне лечения показала более быстрое купирование гиперемии, инфильтрации, возникновение признаков эпителизации мелких эрозий в основной группе - на 3-7-й дни. 
В группе сравнения аналогичные процессы отмечались лишь на 8-10-й дни.

\section{Эффективность симптоматической терапии}

Микроскопия мазка из влагалища в динамике показала, что исчезновение лейкоцитоза к десятому дню терапии зафиксировано у 68,0\% пациенток основной и $39,1 \%$ пациенток группы сравнения. При бактериальном посеве отделяемого из влагалища отмечался выраженный рост лактобацилл к 14-му дню наблюдения в обеих группах. Частота обнаружения лактобацилл в основной группе была выше 92,4 против $65,3 \%$ в группе сравнения. Аэробные бактерии к 14-му дню сохранялись только в группе сравнения - 12,3\% случаев. Кокковая микрофлора присутствовала у 7\% пациенток группы сравнения и $1 \%$ пациенток основной группы.

К 21-му дню отмечалось снижение рН влагалищного содержимого до нормальных цифр у всех пациенток основной группы. У $24 \%$ пациенток группы сравнения сохранялись значения $\mathrm{pH}>4,5$ (рис. 3 ).

Среди побочных эффектов к окончанию курсового лечения у 3 (10\%) пациенток основной группы зарегистрированы зуд и жжение во влагалище. Системных побочных эффектов не зафиксировано.

По завершении курса антибиотикотерапии у больных группы сравнения побочные реакции носили системный характер и проявлялись тошнотой у 14 (46,6\%) пациенток, диспепсическими расстройствами у 8 (26,6\%), головной болью у 11 (36,6\%) пациенток. Побочные эффекты имели слабую и среднюю степень выраженности.

При кольпоскопическом исследовании, выполненном после курсового лечения, прослеживалась отчетливая положительная динамика в виде уменьшения кольпоскопических признаков хронического воспалительного процесса и атипизации эпителия в аномальных зонах трансформации 1-го и 2-го типов $90,0 \%$ случаев в основной группе, $46,4 \%$ - в группе сравнения (таблица).

\section{Выводы}

Эффективность лечения пациенток с хроническими рецидивирующими неспецифическими экзо- и эндоцервицитами и вагинитами на фоне доброкачественных и предраковых (LSIL) заболеваний шейки матки легкой степени составила $88 \%$ в основной группе и $64 \%$ в группе сравнения.

Побочные эффекты у незначительного процента больных основной группы выражались только в местных симптомах, что свидетельствовало о хорошей переносимости комбинированного препарата для интравагинального применения, содержащего орнидазол 500 мг, преднизолон 3 мг, эконазол 150 мг, неомицин $65000 \mathrm{ME}$, по сравнению с метронидазолом и флуконазолом. У пациенток группы сравнения побочные эффекты носили системный характер и проявлялись тошнотой, диспепсическими расстройствами, головной болью и имели слабую и среднюю степень выраженности.
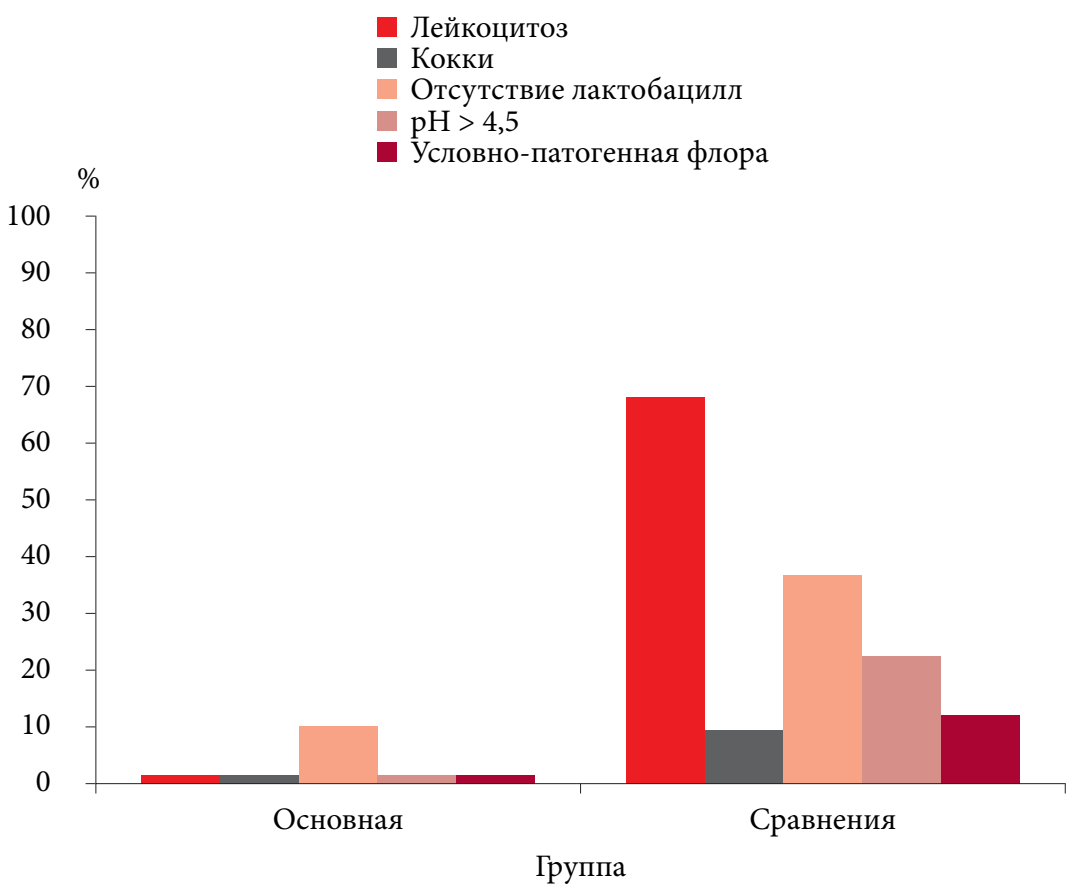

Рис. 3. Лабораторные показатели отделяемого из влагалища у пациенток после лечения

Кольпоскопическое исследование, выполненное после курсового лечения, продемонстрировало отчетливую положительную динамику - уменьшение выраженности признаков хронического воспалительного процесса и атипизацию эпителия в аномальных зонах трансформации 1-го и 2-го типов (90,0\% случаев в основной группе, 46,4\% - в группе сравнения). Иными словами, более выраженный положительный эффект отмечался на фоне местного комбинированного лечения.

\section{Заключение}

Лечение пациенток с хроническими рецидивирующими неспецифическими экзо- и эндоцервицитами и вагинитами на фоне доброкачественных и предраковых (LSIL) заболеваний шейки матки легкой степени требует назначения препаратов, направленных на все звенья патогенеза.

Эффективность терапии в исследуемьх группах

\begin{tabular}{|l|l|l|l|}
\hline Показатели & $\begin{array}{l}\text { Основная } \\
\text { группа, } \\
\text { абс. (\%) }\end{array}$ & $\begin{array}{l}\text { Группа } \\
\text { сравнения, } \\
\text { абс. (\%) }\end{array}$ & p \\
\hline Снижение лейкоцитоза в мазке & $20(66,6)$ & $11(36,6)$ & $<0,005$ \\
\hline Увеличение лактобацилл & $27(90)$ & $19(63,3)$ & $<0,005$ \\
\hline Сохранение аэробной флоры & 0 & $4(13,3)$ & $<0,005$ \\
\hline Нормализация рН & $30(100)$ & $22(73,3)$ & $<0,005$ \\
\hline $\begin{array}{l}\text { Положительная динамика } \\
\text { при кольпоскопическом исследовании }\end{array}$ & $27(90)$ & $13(43,3)$ & $<0,005$ \\
\hline
\end{tabular}


Эффективность интравагинального препарата Эльжина (орнидазол 500 мг, преднизолон 3 мг, эконазол 150 мг, неомицин $65000 \mathrm{ME)}$ превышает таковую комплексной терапии метронидазолом интравагинально в сочетаниии с флуконазолом.

Показана эффективность и безопасность предоперационной подготовки перед этапом хирургического лечения по поводу доброкачественных и предраковых (LSIL) заболеваний шейки матки легкой степени с использованием препарата Эльжина.

Работа выполнена в рамках основного плана научно-исследовательских работ кафедры акушерства и гинекологии Саратовского государственного медицинского университета им. В.И. Разумовского.

\section{Литература}

1. Доброкачественные и предраковые заболевания шейки матки с позиции профилактики рака.

Клинические рекомендации. М., 2017 // spnavigator.ru/dokument/0a7d702f-61a240b9-b9f6-8c1fa7127b0.

2. Кондратьева Ю.С., Неймарк А.И., Алиев Р.Т. Использование макролидов в терапии дизурических расстройств, протекающих на фоне урогенитальных инфекций, у женщин репродуктивного возраста // Российский вестник акушера-гинеколога. 2011. Т. 11. № 1. С. 77-81.

3. Рецидивы баквагиноза и лактофлора: от актуальной неоднозначности к практическим решениям / под ред. В.Е. Радзинского. М., 2013.

4. Савичева А.М. Особенности микробиологической диагностики репродуктивно значимых инфекций // Акушерство и гинекология. 2010. № 4. С. 11-16.

5. Arbyn M., Xu L., Simoens C. et al. Prophylactic vaccination against human papillomaviruses to prevent cervical cancer and its precursors // Cochrane Database Syst. Rev. 2018. Vol. 5. № 5. CD009069.

6. Reid G. Cervicalvaginal microbiomes - threats and possibities // Trends Endocrinol. Metab. 2016. Vol. 27. № 7. P. 446-454.

7. Клинические рекомендации по диагностике и лечению заболеваний, сопровождающихся патологическими выделениями из половых путей женщин // spnavigator.ru/dokument/3070c101-cfae-4ce1-aa146515f8bba7e.

8. Кисина В.И., Забиров К.И., Гущин А.Е. Ведение больных инфекциями, передаваемыми половым путем. М.: ГОЭТАР-Медиа, 2017.

9. Рогожина И.Е., Нейбельд И.В., Столярова У.В. Коррекция нарушения вагинального микробиоценоза у женщин в перименопаузе // Российский вестник акушера-гинеколога. 2014. Т. 14. № 5. С. 87-92.

10. Рогожина И.Е., Нейбельд И.В., Столярова У.В., Скупова И.Н. Оптимизация лечения женщин с рецидивирующими неспецифическими вагинитами и цервицитами // Инфекционные болезни: новости, мнения, обучение. 2017. № 1 (18). С. 70-75.

11. Кузнецова Л.Э. Доброкачественные, фоновые и предраковые заболевания шейки матки // Медицинские новости. 2016. № 4. С. 47-51.

12. Инструкция по медицинскому применению препарата Эльжина ГРЛС, 2021 // grls.rosminzdrav.ru/Grls_View_ v2.aspx?routingGuid $=593 \mathrm{cc} 73 \mathrm{e}-\mathrm{c} 7 \mathrm{f} 0-4 \mathrm{~b} 96-982 \mathrm{c}-\mathrm{b} 54626331 \mathrm{f} 16 \& \mathrm{t}=$

Optimization of the Tactics of Examination and Treatment of Women of Reproductive Age with Cervical Pathology in Chronic Cervicitis and Vaginitis

U.V. Stolyarova, PhD, I.Ye. Rogozhina, PhD, Prof., I.N. Skupova, M.V. Kuznetsova, N.S. Kuznetsov, A.S. Asyrkin V.I. Razumovsky Saratov State Medical University

Contact person: Ulyana V. Stolyarova, stolyarova.ulyana@yandex.ru

The article is a description of the effectiveness of treatment of patients of reproductive age with chronic nonspecific exo-, endocervicitis and vaginitis in the presence of benign and precancerous diseases of the cervix of the uterus of mild degree. Comparative characteristics of the use of the combined preparation for intravaginal administration Elzhina and intravaginal administration of metronidazole with oral fluconazole were carried out. The advantages of using the drug Elzhina in terms of preoperative preparation over the use of radio wave excisional and surgical methods of treatment are noted. The efficacy, tolerability, and safety of the therapy were also evaluated in both treatment options. It is noted that the drug containing ornidazole $500 \mathrm{mg}$, prednisolone $3 \mathrm{mg}$, econazole $150 \mathrm{mg}$, neomycin $65000 \mathrm{IU}$, will reduce the severity of inflammatory processes, which has a beneficial effect on the results of radio wave and surgical methods for the treatment of benign and precancerous diseases of the cervix. Against the background of chronic, long-term nonspecific exo-, endocervicitis and vaginitis.

Key words: pathology of the cervix, cervicitis, vaginitis, reproductive age, Elzhina 


\section{ЭА}

СОВРЕМЕННАЯ СТАРТОВАЯ ТЕРАПИЯ ВАГИНААЬНЫХ ИНФЕКЦИЙ"

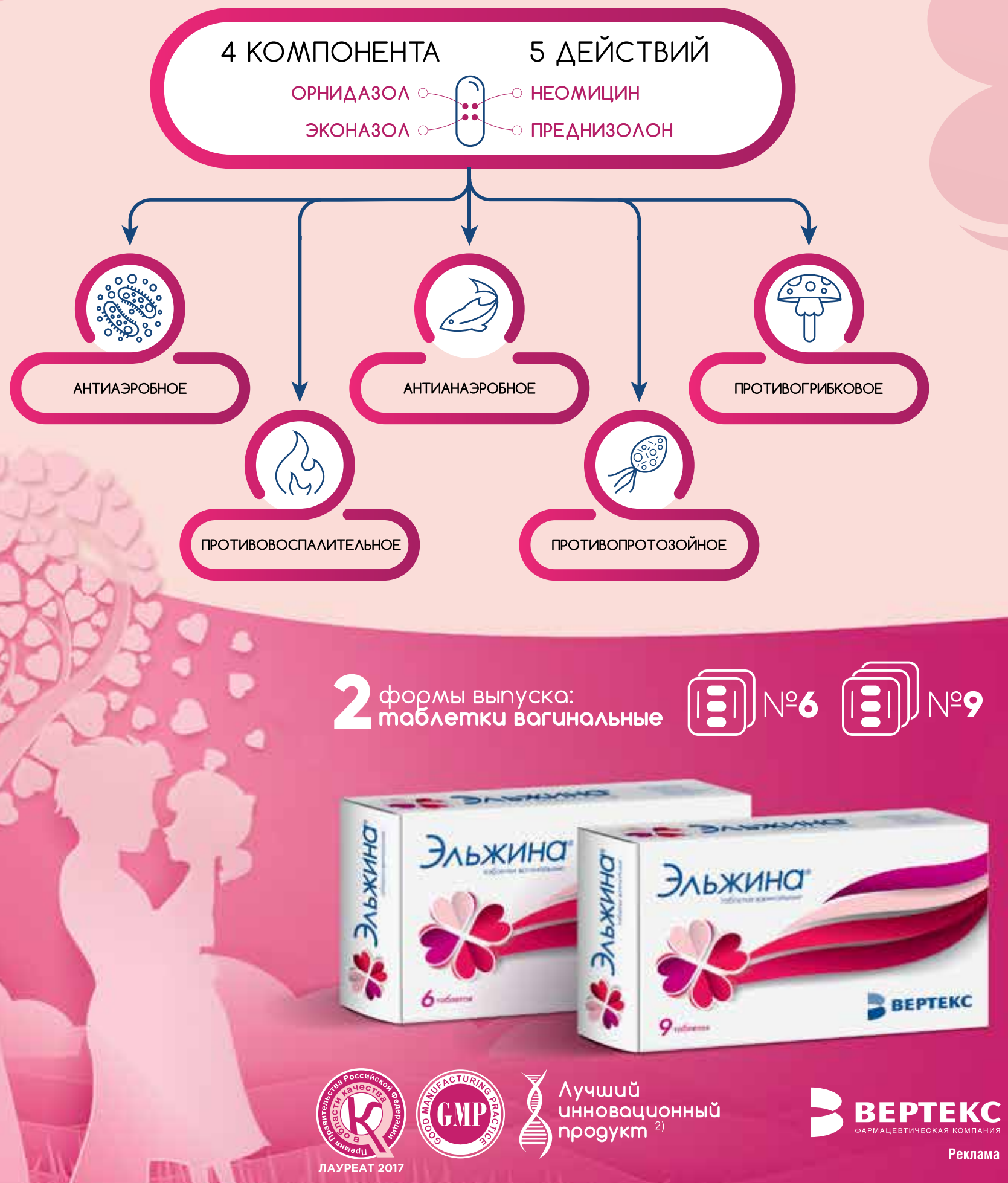

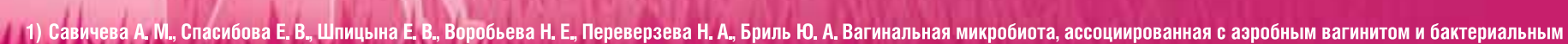
вагинозом: как сориентироваться в «микробном Mире»? // StatusPraesens. Гинекология, акушерство, бесплодный брак. - 2018. - 3 [47]. - С. 51-58.

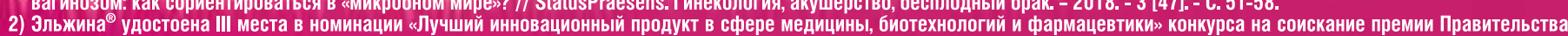
Санкт-Петербурга в 2017 г. 